\title{
We stand by our guidelines
}

Xavier Pi-Sunyer, Michael Jensen, Donna Ryan, Caroline Apovian, Barbara Millen and Cathy Nonas

In their News and Views article (Have new guidelines overlooked the role of diet composition? Nat. Rev. Endocrinol. 10, 132-133; 2014), ${ }^{1}$ Arne Astrup and Jennie Brand-Miller have commented on the 2013 guidelines for the management of overweight and obesity jointly produced by the American Heart Association (AHA), the American College of Cardiology (ACC) and The Obesity Society (TOS). ${ }^{2}$ They conclude with the statement: "The new AHA-ACC-TOS guidelines misinform both clinicians and the public and will not help to solve the global obesity problem." Strong words indeed, but not backed up by convincing evidence.

First, these authors assert that the Institute of Medicine (IOM) criteria for guidelines are inappropriate if applied to dietary intervention trials because "they exclude a vast body of evidence." This statement is the subjective opinion of the authors. The IOM methodology defines adequate evidence for making clinical management recommendations to physicians. The strongest evidence comes from randomized controlled trials with adequate methodology-carried out over a long duration and robust in terms of participant retention-rather than the prospective, observational studies with self-reported outcomes that Astrup and Brand-Miller cite in their article.

Second, these authors contend that the AHA-ACC-TOS guidelines give low ratings to high protein diets and to low glycaemic index (GI) and low glycaemic load (GL) diets. Their defence, a meta-analysis, evaluated the influence of low carbohydrate diets, not high protein diets. ${ }^{3}$ Furthermore, Astrup and Brand-Miller cite a study ${ }^{4}$ that used "metaregression to determine the effects of variations in protein and carbohydrate intakes on body mass and composition during energy restriction." This research reported, however, that in studies conducted for $>12$ weeks "no significant effects of protein intake on loss of either body mass or fat mass were observed."
With regard to GI and GL, Astrup and Brand-Miller simply depend on prospective cohort studies and use their findings to state that high dietary GI and GL increase the relative risk of type 2 diabetes mellitus and coronary heart disease. But this viewpoint, besides being extremely controversial, is not the point at issue, which is whether protein or GI and/or GL lead to increased weight loss.

They cite a study to support that low GL diets produce considerable decreases in weight and body fat content at 18 months among adults with high levels of insulin secretion. ${ }^{5}$ This study recorded a $22 \%$ dropout rate in one diet group and a 36\% drop-out rate in the other; consequently, of the 73 participants originally enrolled only 51 completed the intervention. The researchers reported that "weight loss did not differ between diet groups for the full cohort of 73 participants $(P=0.99)$ " and "...change in body fat percentage also did not differ between diet groups for the full cohort." Thus, a low GL diet given ad libitum did not differ from a diet comprising low fat and high GL for reductions in weight at 6,12 or 18 months.

Finally, a study is referenced in which diets were tested for 4 weeks only in a crossover design and just 21 of 32 patients (66\%) completed the intervention. ${ }^{6}$ The methodology used by the AHA-ACC-TOS guidelines expert panel required diets to be given for a minimum of 6 months and to exhibit low levels of dropout.

To conclude, we stand by both our guidelines and the IOM methodology. The main issue in attempting to succeed with weight loss and weight-loss maintenance is the need for a reduction in energy intake and an increase in energy expenditure. Consequently, the need to get this idea across to physicians and patients is crucial and, therefore, emphasized in the AHA-ACCTOS guidelines. These guidelines put to rest the idea that there is a magic diet that can 'cure' obesity, an important message when so many self-interested promoters of one diet or another compete for attention.

Division of Endocrinology, Diabetes and Nutrition, St Luke's-Roosevelt Hospital Centre, 1111 Amsterdam Avenue, Room 1020, New York, NY 10025, USA (X.P.-S.). Endocrine Research Unit, 5-194 Joseph Building, Mayo Clinic, 200 First Street SW, Rochester, MN 55905, USA (M.J.). Pennington Biomedical Research Centre, 625 St Charles Avenue, New Orleans, LA 70130, USA (D.R.). Section of Endocrinology, Diabetes, and Nutrition, Boston University School of Medicine, 88 East Newton Street, Robinson 4400, Boston, MA 02118, USA (C.A.). Millennium Prevention Boston Nutrition Foundation, PO Box 311, Westwood, MA 02090, USA (B.M.). Bureau of Chronic Disease Prevention and Tobacco Control, New York City Department of Health and Mental Hygiene, Gotham Centre, 42-09 28 ${ }^{\text {th }}$ Street, $9^{\text {th }}$ floor, CN 46, New York, NY 11101, USA (C.N.). Correspondence to: D.R.

ryandh@pbrc.edu

\section{Competing interests}

The authors declare no competing interests.

1. Astrup, A. \& Brand-Miller, J. Have new guidelines overlooked the role of diet composition? Nat. Rev. Endocrinol. 10, 132-133 (2014).

2. Jensen M. D. et al. 2013 AHA/ACC/TOS guideline for the management of overweight and obesity in adults: a report of the American College of Cardiology/American Heart Association Task Force on Practice Guidelines and The Obesity Society. J. Am. Coll. Cardiol. http://dx.doi.org/10.1016/jacc.2013.11.004.

3. Santos, F. L., Esteves, S. S., da Costa Pereira, A., Yancy, W. S. Jr \& Nunes, J. P. Systematic review and meta-analysis of clinical trials of the effects of low carbohydrate diets on cardiovascular risk factors. Obes. Rev. 13, 1048-1066 (2012).

4. Krieger, J. W., Sitren, H. S., Daniels, M. J. \& Langkamp-Henken, B. Effects of variation in protein and carbohydrate intake on body mass and composition during energy restriction: a meta-regression. Am. J. Clin. Nutr. 83, 260-274 (2006).

5. Ebbeling, C. B., Leidig, M. M., Feldman, H. A., Lovesky, M. M. \& Ludwig, D. S. Effects of a low glycemic load vs low-fat diet in obese young adults: a randomized trial. JAMA 297, 2092-2102 (2007).

6. Ebbeling, C. B. et al. Effects of dietary composition on energy expenditure during weight-loss maintenance. JAMA 307 , 2627-2634 (2012). 